\title{
Effect of Maternal Awareness regarding Antenatal Care on Newborn Health in Bangladesh
}

\author{
Manju Ara Khatun ${ }^{*}$, Shanzida Khatun ${ }^{2}$ \\ ${ }^{1}$ Dhaka Nursing College, Dhaka, Bangladesh \\ ${ }^{2}$ National Institute of Advance Nursing Education and Research (NIANER), Mugda, Dhaka, Bangladesh
}

*Corresponding author: Khatun MA, Dhaka Nursing College, Dhaka, Bangladesh, E-mail: manjuarakhatun@ yahoo.com

Citation: Khatun, M.A., and Khatun, S. (2018) Effect of Maternal Awareness regarding Antenatal Care on Newborn Health in Bangladesh. J Nurs Healthcare Manag 1: 101

Article history: Received: 17 December 2017, Accepted: 28 April 2018, Published: 29 April 2018

\section{Abstract}

Introduction: New born care is an effective way to meet the baby's needs which mothers' have been achieved from antenatal care services. This service is extremely important during pregnancy to reduce neonatal and infant mortality and morbidity.

Objective: To assess the effect of maternal awareness regarding antenatal care on newborn health in Bangladesh.

Methods: The study was conducted by using descriptive and cross sectional design with a systematic random sampling technique. This study was approved by the appropriate authority and informed consent forms were obtained from the participants. Four hundred forty two mothers completed three sets of questionnaires: (1) The Demographic Data Questionnaire; (2) Maternal Awareness related Questionnaire; (3) Impact of Awareness Questionnaires. Content validity was done by the experts and internal consistency of these instruments was satisfactory with Cronbach's alpha over 0.74 .

Results: The mean age of the mother's was $24.77 \pm 4.29$ years and 57.9 percent of mother's has received four and more antenatal care visit and only 1.4 percent did not received antenatal care visit. Relationship between number of received antenatal care visit and socio demographic status on education $\left(x^{2}=-4.70, \mathrm{p}<0.001\right)$, employment status $\left(x^{2}=7.57, \mathrm{p} 0.006\right)$, monthly family income $\left(x^{2}=-4.14, \mathrm{p}<0.001\right)$ and length of pregnancy $\left(x^{2}=6.40, \mathrm{p} 0.012\right)$ were statistically significant by Chi-square test analysis. Differences between number of antenatal care visit and effects of newborn health regarding birth weight ( $t=11.199, \mathrm{p} 0.024)$, type of first feeding $(t=10.256, \mathrm{p} 0.036)$, initiation of first feeding $(t=12.149, \mathrm{p} 0.016)$ and exclusive breast feeding $(t=15.929, \mathrm{p} 0.003)$ was significantly different by $\mathrm{t}$-test analysis.

Conclusion: The study exposed that successfully has met the 4 ANC visit which to be achieved by 2016 in Bangladesh. Adding together, the findings of this study were significantly relationship between maternal awareness of antenatal care and outcome of newborn health. The nurse-midwives can provide information to the mothers' to increase their awareness which may help for good health of newborn. Further intervention study is needed for better outcome that may help to achieve the SDGs.

Keywords: Effect; Maternal; Awareness; Antenatal Care; Newborn; Bangladesh

\section{Introduction}

Globally 3.3 million newborns died within the first month of life every year and the proportion of neonatal deaths has increased worldwide which is currently estimated at 41 percent, 90 percent of these deaths occur in developing countries [1,2]. In Bangladesh, neonatal mortality rate is $24 / 1000$ live births, and the rate of stillbirths 36/1000 births low birth weight 33/1000 live births [3-5]. Moreover a study found $22.6 \%$ low birth weight [6]. These deaths and complications have to occur especially during child birth and after delivery due to lack of proper antenatal care or inadequate management of pregnancy $[7,8]$.

Despite several studies revealed that maternal education, lack of access of antenatal care is significant associated with increased risk of stillbirth(s). Low birth weight (LBW) is closely associated with fetal and neonatal mortality and morbidity [9]. Premature birth, poor nutritional status, inadequate nutritional intake during pregnancy, and poverty are the major causes of low birth weight babies [10]. The overwhelming of these deaths could have been prevented through antenatal care visits [11-13].

Antenatal care (ANC) is the care of a mother during pregnancy. ANC visit is an effective tool to provide advice, education, reassurance, and support to improve maternal, perinatal and neonatal outcomes [14-15]. According to WHO CCS, Bangladesh 
2014-17, reported that there has been slow progress antenatal care coverage. Mothers having had only one visit 50.5 percent in 2004 and 54.6 percent in 2011 and having had four visits increased from 16.7 percent in 2004 to 25.5 percent in 2011 [16]. The latest information from Bangladesh Demographic Health Survey that 31 percent pregnant women have received four or more antenatal visits which is still far behind the reaching target of government [17].

The Health Population and Nutrition Sector of Development Programme (HPNSDP) has been initiated the different programme to achieve the Millennium Development Goals 4 by the Ministry of Health and Family Welfare (MOHFW), Government of Bangladesh (GOB) for a period of five years from July 2011 to June 2016. The set target and indicators to be achieved which are NMR from 32/1000 live births to 21/1000 live births, IMR from 43/1000 live births to 31/1000 live births, ANC coverage one visit from $67.7 \%$ to $100 \%$ and four visit from $25.5 \%$ to $50 \%$. Increase the rate of initiation of breastfeeding within one hour after birth, and Increase the rate of Exclusive breastfeeding up to six months by 2016 [17-19].

Antenatal care is one of the programs to meet the set target of the Government which will achieve the Millennium Development Goal 4. Therefore, further it is needed to see the progress of antenatal care service whether or not successfully achieved the set target of Government. There have no published study previously in Bangladesh in this regards. This study intended to assess the effect of antenatal care on newborn health in Bangladesh. The findings can play an important role to help the nurse-midwives to provide adequate information to better understanding of the mothers which can improve their fetus and newborn baby's health.

\section{Conceptual framework}

The conceptual framework of this study guided by the literature on Antenatal care, Millennium Development goals progress report of Government of the Republic of Bangladesh 2012 and WHO Country Cooperation Strategy Bangladesh 2014-2017 to developed conceptual frame work $[3,20,21]$. In this study mainly three domain were used. This includes 1) socio-demographic refers to age, religion, living status, education, occupation, monthly family income, number of family member, number of children, gestational age and condition during pregnancy, 2) antenatal care refers to meaning of ANC, Important of ANC and number of received antenatal care visit, and 3) effect of newborn health refers to birth weight of newborn, type of first feeding, initiation of first feeding, exclusive breastfeeding after birth which are influence by maternal awareness of ANC and socio-demographic characteristics.

\section{Methods}

\section{Setting and Participants}

Participants were recruited from Dhaka Medical College Hospital (DMCH) and Sir Salimullah Medical College Hospital (SSMCH), Mitford, Dhaka, Bangladesh. Mothers' of this study were postpartum mothers. This study was conducted from May 2014 to October 2014 at inpatients department for maternal and child birth care delivery. The sample size was estimated in this study by using statistical formula.

$$
\mathrm{N}=\frac{\mathrm{Z}^{2} \mathrm{p}(1-\mathrm{p})}{\mathrm{d}^{2}} \quad \mathrm{~N}=\frac{(1.96)^{2}(0.5)(0.5)}{(0.05)^{2}}=384.16
$$

However, for $15 \%$ attrition the final sample size for data analysis was four hundred forty two mothers. A systematic random sampling method was used to recruit the eligible subjects in this study. All mothers' met the following inclusion criteria: i) gave childbirth at least one day before, ii) agreed to participate, iii) both healthy and unhealthy mothers'. Disagreed to participate mothers' were excluded from this study. According to section criteria, systematic random sampling techniques were made by distribution of patients' bed. If the selected occupied bed unable to meet the criteria then next occupied bed were included for sampling.

\section{Measure}

Data were collected by using three questionnaires: i) The Demographic data questionnaire, ii) Maternal awareness related questionnaire and ii) Effect on newborn health related questionnaire.

The Demographic Data Questionnaire: The Demographic Data Questionnaire The Demographic Data Questionnaire was designed by the researcher, based on the literature review. The characteristics of mothers' consisted of age, religion, living place, education, occupation, monthly family income, number of family member, number of children, length of pregnancy and condition during pregnancy.

Maternal awareness related questionnaire: Maternal' awareness of ANC questionnaire was designed by the researcher, based on literature review. It consisted of meaning of ANC, Important of ANC and number of received antenatal care visit.

Impact of Awareness Questionnaires: Outcome of newborn health was measured by the Impact of Awareness Questionnaires developed based on the literature review. Newborn health consisted of birth weight, type of first feeding after birth, starting time of first feeding after birth, exclusive breastfeeding after birth. 


\section{Validity and Reliability}

The content validity of the instruments was completed by experts from obstratic \& gynecologists, pediatrics, and nursing specialists. The researcher reviewed and revised all instruments using the experts' suggestions. Pilot study was conducted with thirty postpartum mothers who had the same inclusion criteria as the subjects of this study. The internal consistency and reliability of the instruments were tested using Cronbach's alpha coefficient, with an acceptable level of at least 0.70 [22]. In this study Cronbach's alpha coefficients was satisfactory for the study variables.

\section{Data collection:}

A descriptive approach was used. Data were collected through self-report questionnaires. After getting permission from the Directors of DMCH and SSMC Mitford Hospital, the researcher met with the charge nurse of the selected ward and the participants who met the inclusion criteria. The researcher introduced herself and briefly explained the purpose of the study and explained informs consent and that mother' had a right to refuse to participate in the study at any time. Then the researcher asked participants to provide answers in accordance with the questions being asked. The individual interview was conducted for 15 minutes.

Data analysis:

Both descriptive and inferential statistics were used to analyze the data. Descriptive statistics were used to analyze the characteristics of mothers. The differences between maternal demographic information and awareness with the number of ANC visits were analyzed using t-test. The correlations between demographic information and effect of newborn health with number of ANC visits were analyzed using chi-square test.

\section{Ethical Consideration}

This study was a part of Doctoral Thesis and it was an own pay distance learning (American World University, USA). Permission was taken from appropriate authority. Then researcher took written permission from Director of DMCH and SSMCH, Mitford, Dhaka for data collection. Written consent obtained from the mother's. All mothers were informed about the study purposes and methods and also said that there is no risk for giving information, no obligation to attend this study, and you can withdraw any time, and confidentiality strictly maintain.

\section{Result}

\section{Participants}

A total of four hundred forty two postnatal mothers gave child birth who participated in this study. The mean age of mothers was $24.77 \pm 4.29$ years. Most of the mothers (50\%) had primary level education and majority of was Muslim (83.7\%). A large number of mothers had no paid employment (95\%), however, the average monthly family income was $9524.89 \pm 4748.96$ Tk. Of mothers'. Majority (52.3\%) of mothers was single family, more than half (55.9\%) had $\geq 2$ children. $76.9 \%$ mother's family member were $\geq 4$ persons. The average pregnancy duration was $37.13 \pm .86$ weeks. A majority $81.7 \%$ mother's duration of pregnancy was $\geq 37$ weeks, and majority $97.5 \%$ mothers had no complication during pregnancy (Table 1).

\begin{tabular}{|c|c|c|c|c|}
\hline Characteristics & Categories & $\mathbf{n}$ & $\%$ & $\mathrm{M} \pm \mathrm{SD}$ \\
\hline \multirow{2}{*}{ Age in years } & $<26$ & 255 & 57.7 & \multirow{2}{*}{$24.77 \pm 4.29$} \\
\hline & $\geq 26$ & 187 & 42.3 & \\
\hline \multirow{3}{*}{ Education level } & Illiterate & 75 & 17.0 & \\
\hline & Primary & 221 & 50.0 & \\
\hline & Secondary \& more & 146 & 33.0 & \\
\hline \multirow{2}{*}{ Religion } & Islam & 370 & 83.7 & \\
\hline & Hindu & 72 & 16.3 & \\
\hline \multirow{2}{*}{ Living place } & Urban & 201 & 45.5 & \\
\hline & Rural & 241 & 54.5 & \\
\hline \multirow{2}{*}{ Employment status } & Employed & 22 & 5.0 & \\
\hline & Unemployed & 420 & 95.0 & \\
\hline \multirow{2}{*}{$\begin{array}{l}\text { Monthly family income } \\
\text { (TK.) }\end{array}$} & $<10000$ & 276 & 62.4 & \multirow{2}{*}{$9524.89 \pm 4748.96$} \\
\hline & $\geq 10000$ & 166 & 37.6 & \\
\hline \multirow{2}{*}{ Type of family } & Single & 231 & 52.3 & \\
\hline & Joint & 211 & 47.7 & \\
\hline \multirow{2}{*}{$\begin{array}{l}\text { Number of family } \\
\text { member }\end{array}$} & $<4$ & 102 & 23.1 & \\
\hline & $\geq 4$ & 340 & 76.9 & \\
\hline
\end{tabular}




\begin{tabular}{|c|c|c|c|c|}
\hline Characteristics & Categories & $\mathbf{n}$ & $\%$ & M \pm SD \\
\hline \multirow{2}{*}{ Number of children } & $<2$ & 195 & 44.1 & \\
\cline { 2 - 5 } & $\geq 2$ & 247 & 55.9 & \\
\hline \multirow{2}{*}{ Length of Pregnancy } & $<37$ wks & 81 & 18.3 & \multirow{2}{*}{$37.13 \pm .86$} \\
\cline { 2 - 5 } & $\geq 37$ wks & 361 & 81.7 & \\
\hline \multirow{2}{*}{$\begin{array}{c}\text { Complication during } \\
\text { pregnancy }\end{array}$} & No problem & 431 & 97.5 & \\
\cline { 2 - 5 } & Problem & 11 & 2.5 & \\
\hline
\end{tabular}

Table 1: General characteristics of Mothers $(N=442)$

\section{Distribution of mothers' awareness}

Table 2 showed distribution of mothers by utilization of antenatal care visit during pregnancy. The mean ANC visits was $3.36 \pm$ 1.10. Most $57.9 \%$ of the mothers had received four and more visits and only $1.4 \%$ of the mothers did not receive antenatal care visit.

\begin{tabular}{|c|c|c|c|c|}
\hline Characteristics & Categories & $\mathbf{n}$ & $\%$ & $\mathrm{M} \pm \mathrm{SD}$ \\
\hline \multirow{2}{*}{ Meaning of ANC } & Know & 416 & 94.1 & \\
\hline & Don't know & 26 & 5.9 & \\
\hline \multirow{2}{*}{$\begin{array}{c}\text { Importance of } \\
\text { ANC }\end{array}$} & Know & 426 & 96.4 & \\
\hline & Don't know & 16 & 3.6 & \\
\hline \multirow{5}{*}{$\begin{array}{l}\text { Number ANC visit } \\
\text { received }\end{array}$} & No visit & 6 & 1.4 & \multirow{5}{*}{$3.36 \pm 1.10$} \\
\hline & One visit & 24 & 5.4 & \\
\hline & Two visit & 96 & 21.7 & \\
\hline & Three visit & 60 & 13.6 & \\
\hline & Four \& more visits & 256 & 57.9 & \\
\hline
\end{tabular}

Table 2: Distribution of Maternal awareness $(N=442)$

Differences in number of antenatal care visit according to demographic characteristics

Table 3 shows the differences in utilization of number of antenatal care visit according to demographic characteristics. Number of ANC visit was statistically highly significantly different by the level of education $(t=-4.70, \mathrm{p}<0.001))$, employment status $(t=7.57, \mathrm{p}$ $0.006)$, and monthly family income $(t=-4.14, \mathrm{p}<0.001)$. The utilization of number of ANC visit were also significantly different by religion of mother and length of Pregnancy ( $t=6.07, \mathrm{p} 0.014$, and $t=6.40, \mathrm{p} 0.012)$.

\begin{tabular}{|c|c|c|c|c|c|c|}
\hline \multirow{2}{*}{ Characteristics } & \multirow{2}{*}{ Categories } & \multicolumn{5}{|c|}{ Number of ANC visit } \\
\hline & & No. visit & $<4$ & $\geq 4$ & $\mathrm{X}^{2}(\mathrm{p})$ & $t / F(p)$ \\
\hline \multirow{2}{*}{ Age of mothers in years } & $<26$ & 4 & 99 & 152 & \multirow{2}{*}{$.715(0.699)$} & \multirow{2}{*}{$2.43(0.119)$} \\
\hline & $\geq 26$ & 3 & 80 & 104 & & \\
\hline \multirow{3}{*}{ Education level } & Illiterate & 1 & 47 & 27 & \multirow{3}{*}{$26.950(<0.001)$} & \multirow{3}{*}{$-4.70(<0.001)$} \\
\hline & Primary & 6 & 88 & 127 & & \\
\hline & Secondary + more & 0 & 44 & 102 & & \\
\hline \multirow{2}{*}{ Religion } & Muslim & 7 & 154 & 209 & \multirow{2}{*}{$2.875(0.238)$} & \multirow{2}{*}{$6.07(0.014)$} \\
\hline & Hindu & 0 & 25 & 47 & & \\
\hline \multirow{2}{*}{ Living place } & Urban & 0 & 78 & 123 & \multirow{2}{*}{$6.782(0.034)$} & \multirow{2}{*}{$3.10(0.079)$} \\
\hline & Rural & 7 & 101 & 133 & & \\
\hline \multirow{2}{*}{ Employment status } & Unemployed & 7 & 173 & 240 & \multirow{2}{*}{$2.243(0.326)$} & \multirow{2}{*}{$7.57(0.006)$} \\
\hline & Employed & 0 & 6 & 16 & & \\
\hline \multirow{2}{*}{$\begin{array}{l}\text { Monthly family income } \\
\text { (TK.) }\end{array}$} & $<10000$ & 7 & 131 & 138 & \multirow{2}{*}{$20.972(<0.001)$} & \multirow{2}{*}{$-4.14(<0.001)$} \\
\hline & $\geq 10000$ & 0 & 48 & 118 & & \\
\hline \multirow{2}{*}{ Type of family } & Single & 3 & 98 & 130 & \multirow{2}{*}{$.917(0.632)$} & \multirow{2}{*}{$2.11(0.147)$} \\
\hline & Joint & 4 & 81 & 126 & & \\
\hline \multirow{2}{*}{$\begin{array}{l}\text { Number of family } \\
\text { member }\end{array}$} & $<4$ & 1 & 40 & 61 & \multirow{2}{*}{$.440(0.803)$} & \multirow{2}{*}{$.52(0.470)$} \\
\hline & $\geq 4$ & 6 & 139 & 195 & & \\
\hline \multirow{2}{*}{ Number of children } & $<2$ & 1 & 76 & 118 & \multirow{2}{*}{$3.132(0.209)$} & \multirow{2}{*}{$2.28(0.131)$} \\
\hline & $\geq 2$ & 6 & 103 & 138 & & \\
\hline
\end{tabular}




\begin{tabular}{|c|c|c|c|c|c|c|}
\hline \multirow{2}{*}{ Characteristics } & \multirow{2}{*}{ Categories } & \multicolumn{5}{|c|}{ Number of ANC visit } \\
\cline { 2 - 6 } & & No. visit & $<4$ & $\geq \mathbf{4}$ & $\mathbf{X}^{\mathbf{2}}(\mathbf{p})$ & $\mathbf{t} / \mathbf{F}(\mathbf{p})$ \\
\hline \multirow{2}{*}{\begin{tabular}{c} 
Length of Pregnancy \\
\cline { 2 - 6 }
\end{tabular}} & $<37$ wks & 1 & 38 & 42 & \multirow{2}{*}{$1.715(0.424)$} & \multirow{2}{*}{$6.40(0.012)$} \\
\hline \multirow{2}{*}{$\begin{array}{c}\text { Complication during } \\
\text { pregnancy }\end{array}$} & Yes & 0 & 6 & 5 & \multirow{2}{*}{$1.031(0.597)$} & \multirow{2}{*}{$3.34(0.068)$} \\
\cline { 2 - 5 } & No & 7 & 173 & 251 & & \\
\hline
\end{tabular}

Table 3: Differences in receiving ANC visit according to demographic characteristics $(N=442)$

\section{Relationship between number of ANC visit according to maternal awareness}

Table 4 shows the correlation between maternal awareness and received number of antenatal care visit. Number of ANC visit was statistically highly significantl correlation with the meaning of antenatal care $\left.\left(\mathrm{x}^{2}=56.149, \mathrm{p}<0.001\right)\right)$ and important of antenatal care $\left(\mathrm{x}^{2}=59.559, \mathrm{p}<0.001\right)$ by chi-square analysis.

\begin{tabular}{|c|c|c|c|c|c|}
\hline \multirow{2}{*}{ Characteristics } & \multirow{2}{*}{ Categories } & \multicolumn{4}{|c|}{ Received Number of ANC visit } \\
\hline & & No. visit & $<4$ & $\geq 4$ & $\mathrm{x}^{2}(\mathbf{p})$ \\
\hline \multirow{2}{*}{ Meaning of ANC } & Know & 2 & 168 & 246 & \multirow{2}{*}{$\begin{array}{c}56.149 \\
(<0.001)\end{array}$} \\
\hline & Don't know & 5 & 11 & 10 & \\
\hline \multirow{2}{*}{ Importance of ANC } & Know & 3 & 172 & 251 & \multirow{2}{*}{$\begin{array}{c}59.559 \\
(<0.001)\end{array}$} \\
\hline & Don't know & 4 & 7 & 5 & \\
\hline
\end{tabular}

Table 4: Differences in received number of ANC visit according to maternal awareness ( $N=442)$

\section{Relationship between number of ANC visit according to effect on newborn health}

Table 5 shows the relationship between numbers of antenatal care visit on newborn health. It was observed that relationship of received number of ANC visit was statistically significantly correlated with the birth weight of newborn ( $t=-11.199, \mathrm{p} 0.024)$ ), type of first feeding after birth $(t=10.256, \mathrm{p} 0.036)$, initiation of firth feeding after birth $(t=12.149, \mathrm{p} 0.016)$, and exclusive breastfeeding after $(t=15.929, \mathrm{p} 0.003)$.

\begin{tabular}{|c|c|c|c|c|c|}
\hline \multirow{2}{*}{\multicolumn{2}{|c|}{$\begin{array}{c}\text { Categories } \\
\text { Characteristics }\end{array}$}} & \multicolumn{4}{|c|}{ Received Number of ANC visit } \\
\hline & & \multirow{2}{*}{$\frac{\text { No. visit }}{1}$} & \multirow{2}{*}{$\begin{array}{l}<4 \\
28\end{array}$} & \multirow{2}{*}{$\begin{array}{l}\geq 4 \\
39\end{array}$} & $\mathbf{x}^{2}(\mathbf{p})$ \\
\hline \multirow{3}{*}{ Birth weight of newborn } & $<2.5 \mathrm{~kg}$ & & & & \multirow{3}{*}{$11.199(0.024)$} \\
\hline & $\geq 2.5 \mathrm{~kg}$ & 4 & 142 & 209 & \\
\hline & Stillbirth & 2 & 9 & 8 & \\
\hline \multirow{3}{*}{$\begin{array}{l}\text { Type of feeding after } \\
\text { birth }\end{array}$} & Colostrum & 5 & 149 & 210 & \multirow{3}{*}{$10.256(0.036)$} \\
\hline & Prelacteal feed & 0 & 21 & 36 & \\
\hline & No feed & 9 & 9 & 10 & \\
\hline \multirow{3}{*}{$\begin{array}{l}\text { Starting time of first } \\
\text { feeding } \\
\text { after birth }\end{array}$} & 1 hour & 1 & 16 & 14 & \multirow{3}{*}{$12.149(0.016)$} \\
\hline & $>$ 1hour & 4 & 154 & 232 & \\
\hline & No feed & 2 & 9 & 10 & \\
\hline \multirow{3}{*}{$\begin{array}{l}\text { Exclusive breastfeeding } \\
\text { after birth }\end{array}$} & Yes & 5 & 163 & 219 & \multirow{3}{*}{$15.929((0.003)$} \\
\hline & Mixed feed & 0 & 7 & 27 & \\
\hline & No & 2 & 9 & 10 & \\
\hline
\end{tabular}

Table 5: Differences in received number of ANC visit according to effect on newborn health $(N=442)$

\section{Discussion}

The present study examined the effects of newborn health among mothers' with antenatal care in Bangladesh. Four hundred forty two mothers' were recruited by systematic random sampling in this study. The present study determined the effect of antenatal care visit among the mothers on newborn health in Bangladesh. The present findings indicated that the differences in effect of antenatal care visit according to demographic characteristics. It was observed that number of ANC visit among mothers were statistically highly significantly different by level of education $(t=-4.70, \mathrm{p}<0.001)$ ), employment status $(t=7.57, \mathrm{p} 0.006)$, monthly family income $(t=-4.14, \mathrm{p}<0.001)$ and length of Pregnancy $(t=6.07, \mathrm{p} 0.012)$. A study was revealed that pregnant mothers' awareness found significant with their education but did not significant with the monthly family income [15,23]. Studies reported, length of pregnancy is the most important for effective outcome of mothers and newborn health. Antenatal care module revealed that quality of care is important and women's perceptions of their care should be sought and considered to prevent complications during pregnancy at all stages $[15,23,24]$.

The current study found that $57.9 \%$ of the mothers received four and more ANC visit which has achieved the set target of government. Only 1.4 percent did not receive the ANC visit due to money problem and far from home to antenatal clinic. 
Bangladesh Demographic Health Survey reported that antenatal care has been slow progress. Mothers have received four ANC visits only 25.5 percent in 2011 which increased 31 percent in 2014. Moreover, 21 percent of the women had no received ANC visit $[18,19]$. Bangladesh demographic health survey stated thwat the importance of ANC is the reduction of maternal morbidity and mortality by utilization of ANC services remains low in Bangladesh and several factors contributing to the low utilization of antenatal care [25].

The Ministry of Health and Family Welfare (MOHFW) initiated the Health, Population, Nutrition Sector Development Program (HPNSDP) for five years, from July 2011 to June 2016 [17,18]. The main objectives of the HPNSDP are to create conditions that allow the Bangladeshi people to reach and maintain the highest attainable level of health as a fundamental human right and an issue of social justice. Antenatal care service is one of the programme which is working toward achieving Millennium Development Goals 4 and 5 (child mortality and maternal health) [19]. The present study though found satisfactory findings with the effect of antenatal care visit on newborn health. But there have some limitations which may not meet the representative in Bangladesh. So this type of study further should be implement in community based which represent the whole population in Bangladesh.

\section{Implications for Nursing Practice}

Nurse-midwife can encourage to take antenatal care visit to the pregnant mothers for good health of mothers as well as newborn health. This study will help the Nurse-midwife for the prevention of pregnancy related problems and health promotion of mothers and newborn.

\section{Implications for Future Studies}

Future study is needed to identify the factors related to maternal antenatal care on effect of newborn health with diverse setting. Further intervention study is also needed to evaluate the effect of intervention on child health outcomes. These may to improve mothers and newborn health in Bangladesh and also help to achieve the SDGs.

\section{Limitations}

Data were collected only from two medical college hospitals. Therefore, this result may not be generalized to other population.

\section{Conclusion}

This study demonstrated the implication of the antenatal care to assess the effect of antenatal care visit on newborn health. According to Government set target 50 percent of pregnant women at least four ANC visits to be achieved by 2016. The current study revealed that 57.9 percent mothers' have received four and more antenatal care visit which covered the set target of Government. Addition together, the findings of this study was significantly relationship between maternal awareness of antenatal care and effects of newborn health. So antenatal care (ANC) visit is the crucial for mother's to improve better health of newborn which can achieve the SDGs.

\section{Acknowledgement}

First of all, thanks to Allah S.W.T for giving me the strength to complete my study. Then gratitude my PhD Supervisor Dr. Md. Manjur Hossain, Assistant Professor, Dept. of Health \& Medical Science, American World University, USA. Sincere thanks to all postpartum mothers who participated in this study.

\section{References}

1. World Health Organization (2014) Global targets 2025. To improve maternal, infant and young child nutrition.

2. World Health Organization (2006) Neonatal and perinatal mortality: country, regional and global estimates.

3. Statistics, Bangladesh, UNICEF Strategic plan 2014-2017.

4. Countdown (2015) Fulfilling the Health Agenda for Women and Children. The 2014 Report. Maternal, Newborn and Child Survival.

5. Nahar S, Rahman A, Nasreen HE (2013) Factors influencing stillbirth in Bangladesh: a case-control study. Paediatr Perinat Epidemiol. 27 : 158-64.

6. National low birth weight survey CIRDA auditorium in Dhaka (2015).

7. Millennium Development Goals (2015) Facts sheet.

8. Bangladesh Demographic Health Survey, National Institute of Population Research and Training, and MOHFW (2011).

9. Bangladesh Maternal Mortality Survey (2010).

10. Viengsakhone LP, Yoshida Y, Harun, RMD, Sakamoto J (2010) Factors affecting low birth weight at four central hospitals in ientiane, lao PDR. Nagoya J Med Sci 72: 51-8.

11. Hashima E, Nahar K, Yvonne F, Maigun E (2010) Low birth weight in offspring of women with depressive and anxiety symptoms during pregnancy: results from a population based study in Bangladesh. BMC Public Health 10: 515.

12. Lawn J, Cousens S, Zupan J (2005) Neonatal Survival Steering Team. 4 million neonatal deaths: When? Where? Why? Lancet 365: 891-900.

13. Lozoff B, Beard J, Connor J, Barbara F, Georgieff M, et al. (2006) Long lasting neural and behavioral effects of iron deficiency in infancy. Nutr Rev 64: S34-43.

14. Projahnmo (2008) Home based interventions in Bangladesh show significant reduction in neonatal mortality.

15. Antenatal care Module-13 (2017) Providing Focused Antenatal Care, portable of age generated. 
16. Dhange P, Breeze ACG, Kean LH (2013) Routine antenatal management at the booking clinic. Obstet Gynaecol Reprod Med. 23: 45-52.

17. World Health Organization, Country Office for Bangladesh (2014) World Health Organization, Country Cooperation Strategy, Bangladesh, $2014-2017$.

18. Bangladesh Demographic Health Survey (2011).

19. Bangladesh Demographic Health Survey (2014).

20. National Institute of Population Research and Training (2013).

21. Bangladesh Progress Report (2012) Millennium Development Goals.

22. Polit DF, Beck CT (2008) Nursing research: Generating and assessing evidence for nursing practice (8th edn). Philadephia: Lippincott Williams \& Wilkins.

23. World Health Organization (2002) Essential Antenatal, Perinatal and Postnatal Care. Training modules, Regional Office for Europe.

24. Bangladesh Demographic Health Survey (2007).

25. WHO, UNICEF, UNFPA, World Bank Group, and the United Nations Population Division (2015) Trends in Maternal Mortality: 1990 to 2015. World Health Organization, Geneva. 